\title{
Some similarities in dietary clusters of pre-school children and their mothers
}

\author{
Marja-Leena Ovaskainen ${ }^{1 *}$, Jaakko Nevalainen ${ }^{2}$, Liisa Uusitalo ${ }^{2}$, Jetta J. Tuokkola ${ }^{3}$, Tuula Arkkola ${ }^{3,4}$, \\ Carina Kronberg-Kippilä ${ }^{1}$, Riitta Veijola ${ }^{4}$, Mikael Knip ${ }^{5,6}$ and Suvi M. Virtanen ${ }^{1,2,5}$ \\ ${ }^{1}$ Nutrition Unit, Department of Health Promotion and Chronic Disease Prevention, National Public Health Institute (KTL), \\ Mannerheimintie 166, 00300 Helsinki, Finland \\ ${ }^{2}$ Tampere School of Public Health, University of Tampere, Tampere, Finland \\ ${ }^{3}$ Department of Public Health, University of Helsinki, Helsinki, Finland \\ ${ }^{4}$ The Department of Pediatrics, University of Oulu, Oulu, Finland \\ ${ }^{5}$ Department of Pediatrics, Tampere University Hospital Research Unit, Tampere, Finland \\ ${ }^{6}$ Hospital for Children and Adolescents, University of Helsinki, Helsinki, Finland
}

(Received 15 July 2008 - Revised 14 November 2008 - Accepted 26 November 2008 - First published online 2 March 2009)

The diet of pre-school children is determined by the parents and carers. The aim of the present study was to describe dietary clusters of pre-school children and their mothers in Finland, and analyse the similarity of dietary clusters within child-mother pairs. The present study comprised the mothers ( $n$ 4862) whose child was recruited in the Type 1 Diabetes Prediction and Prevention Nutrition Study and the children belonging to selected, cross-sectional age groups of 1 year $(n$ 719), 3 years $(n 708)$ and 6 years $(n$ 841). The dietary data were collected from children by 3 - $\mathrm{d}$ food records and from mothers by a FFQ validated for pregnant women. The food consumption data were analysed for patterns by hierarchical cluster analysis. Three main dietary clusters were identified in children: 'healthy' and 'traditional' in all three age groups, and 'ready-to-eat baby foods' in 1-year-olds and 'fast foods, sweet' in the older children. Six main clusters were identified among the mothers who completed a FFQ for their diet during pregnancy. Some familial dependence between dietary clusters of mother-child pairs was observed in 6-year-old children but not in younger children. Younger age and lower educational level of the mother were associated with the cluster 'fast food, sweet' only at the age of 3 years. The diets of pre-school children vary by age and only a slight similarity within dietary clusters of mother-child pairs was observed.

Children: Mothers: Dietary cluster: Food consumption: Social background

Food preferences, likes and dislikes for food items, are developed in early childhood ${ }^{(1)}$. Parents and carers determine the food behaviour ${ }^{(1,2)}$ of infants and toddlers by the availability of food. Maternal attitudes and health behaviour may influence children's food patterns but the implications for the child's diet may still differ from the mother's own $\operatorname{diet}^{(1-3)}$. Previous evidence suggests similarity of food habits in a family, and especially between diets of mothers and their children ${ }^{(3-8)}$. Traditional and health-conscious food choices established in childhood were observed to remain even in adulthood ${ }^{(9)}$.

Complementary feeding of the child has started with infant formulas at the average age of 2 months in Finland ${ }^{(10,11)}$. Mashed vegetables, fruits and other solids follow after the age of 4-5 months ${ }^{(7,11-14)}$. Beside home-made food, manufactured baby foods ${ }^{(15)}$, convenience foods ${ }^{(16)}$ and other manufactured food products ${ }^{(17)}$ are part of the childhood diet. Conveniencerelated quality of food is determined ${ }^{(17)}$ to be associated with reducing the time or other input required in food shopping, preparation or cooking the meal. The nutritional composition of manufactured food products has been discussed due to their dried, isolated or condensed ingredients ${ }^{(15)}$.
Child health-care clinics give advice about feeding practices to the mothers of almost all infants in Finland ${ }^{(10,18)}$. Nutrition counselling aims at promoting breast-feeding and encourages a balanced diet. Healthy food choices such as consumption of skimmed milk, whole-grain bread, and fruits and vegetables are emphasised in child health-care clinics in contrast to undesirable food behaviour, for example the consumption of highenergy snacks ${ }^{(2,6,19-22)}$. The consumption of sugar-sweetened beverages has increased in the past decade and is under consideration due to replacing more nutritious beverages ${ }^{(19,23)}$. The consumption of high-sugar food products has been reported to be associated with mothers and their children at least in infants ${ }^{(8)}$, in 2-year-olds ${ }^{(2)}$ and in 5-year-old daughters ${ }^{(5)}$.

Cluster analysis has been used in three dietary surveys of infants or toddlers, which resulted in six ${ }^{(24)}$ and seven clusters $^{(25)}$ or analysed beverages only ${ }^{(26)}$. Dietary patterns have been analysed more frequently by either principal component analysis $^{(7,27-29)}$ or factor analysis ${ }^{(29,30)}$ in early childhood. The present study has the benefit of having dietary data for the child-mother pairs, which enables to study the similarity of dietary clusters within these dyads. The aim of the present

Abbreviations: DIPP, Diabetes Prediction and Prevention; FR, food records.

* Corresponding author: Dr Marja-Leena Ovaskainen, fax +358 94744 8591, email marja-leena.ovaskainen@ktl.fi 
study is to define the dietary clusters in the mothers and in three age groups of children in the Diabetes Prediction and Prevention (DIPP) Nutrition Study. The present study also elucidates similarities of dietary clusters within the mother-child dyads. The associations of social background factors with the clusters predicting selections of convenient foods (including ready-to-eat baby foods and fast foods) within the children were determined.

\section{Subjects and methods}

In the DIPP Study ${ }^{(31)}$, newborn infants from the areas of three university hospitals in Finland were screened for HLA-DQB1 conferred susceptibility to the type 1 diabetes using cord blood samples. Infants carrying increased genetic susceptibility (HLA-DQB $1 * 02 / 0302$ heterozygous and DQB $1 * 0302 / \mathrm{x}$-positive subjects; $\mathrm{x}$ stands for homozygosity or a neutral allele) belong to cohorts being monitored for diabetes-associated auto-antibodies at 3-12-month intervals. The procedures of the study were approved by the local Ethics Committees. The mother or other representative of the family signed informed written consents.

\section{Children and their mothers with dietary data}

The DIPP Nutrition Study falls within the framework of the DIPP Study ${ }^{(32)}$ and was carried out in two university hospitals (Oulu and Tampere). The present study comprises the at-risk children ( $n$ 2268) belonging to time-restricted, crosssectional age groups on annual visits in 2003-2004. The food consumption was collected by 3 -d food records (FR) about the first ( $n$ 719), third ( $n$ 708) or sixth ( $n$ 841) birthday. The FR covered both weekdays and weekend and separate forms were provided for the day care. The parents and day carers were instructed to record all the foods and drinks by estimated portions as volume or pieces. The FR was checked by a trained nurse in the study centre at annual visit. The FR were entered into a dietary database using standard volumeto-weight conversions by in-house software. Food consumption was aggregated to average daily food use $(\mathrm{g} / \mathrm{d})$ by the food classification of the food composition database ${ }^{(33)}$. Children's sex and day care (home/outside home) during recording days were entered as background factors.

The mothers participating in the DIPP Nutrition Study (n 4939) gave postnatal estimation of their diet during the 8th month of pregnancy ${ }^{(34)}$. The dietary data of the mothers were enquired by a 181-item FFQ, which was specifically developed and validated for the present study design ${ }^{(34)}$. Detailed information of the procedures of the FFQ and social background of the mothers has been described earlier ${ }^{(35)}$. If frequency data were inconsistent or there were ten or more food items with missing frequency data, the questionnaire was rejected $(1.6 \%)$ from the analyses. Other missing frequencies were imputed as zero. Daily energy intake and the consumption $(\mathrm{g} / \mathrm{d})$ of food items were calculated by food classification described in the earlier report ${ }^{(35)}$. The cluster analysis was carried out in all the mothers of the DIPP Nutrition Study. The effect of omitted frequencies of the FFQ was studied by sensitivity analysis of dietary clusters, and no association between omitting frequencies and clusters was observed.

The social factors of the mother and the family were enquired and entered into the study data covering age, basic and professional education, and number of siblings. The matching pairs of a child and the mother were picked to study the familial association of dietary clusters within the dyads (Fig. 1). Some mothers were included twice (n 134) in the pair analyses of the present study because they had twins ( $n$ 42) or their children were represented in two (or three) age groups.

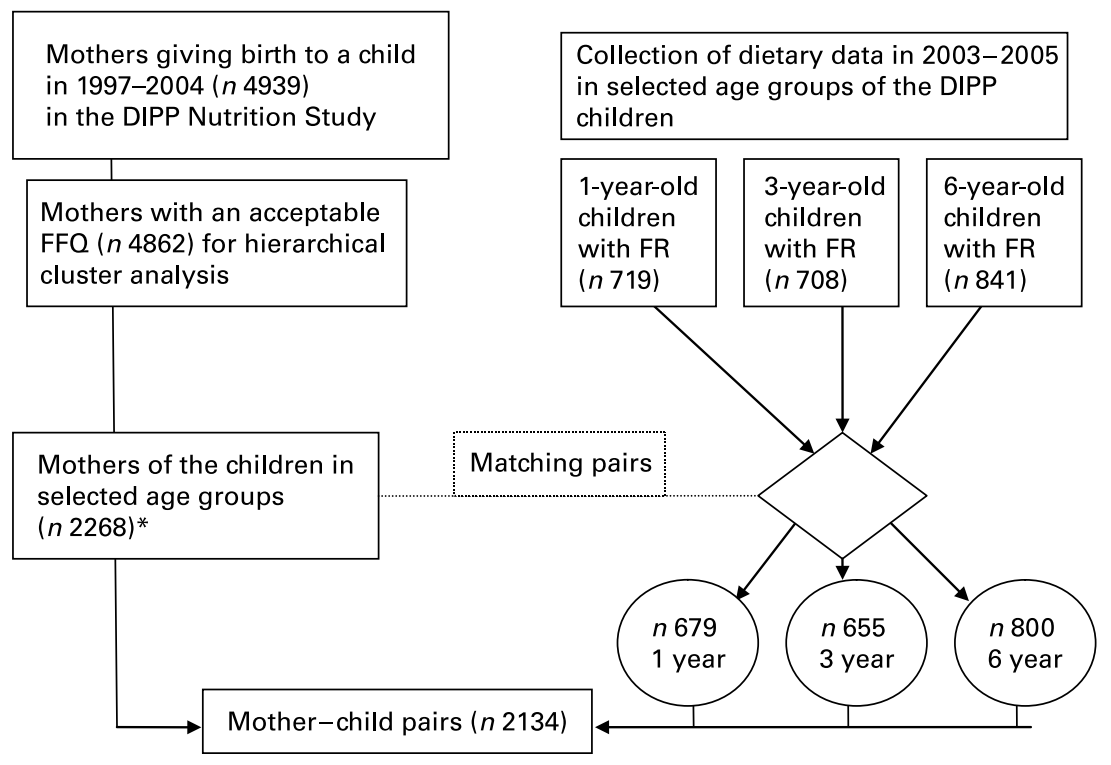

Fig. 1. Flow diagram of mothers and children used for the comparison of dietary clusters in the mother-child pairs of the Diabetes Prediction and Prevention (DIPP) Nutrition Study. ${ }^{*}$ Some mothers had twins or children in two age groups. FR, food record. 
Table 1. Spearman's correlation coefficients for food groups with three dietary clusters in 1-, 3- and 6-year-old children in the Diabetes Prediction and Prevention Nutrition Study

\begin{tabular}{|c|c|c|c|c|c|c|c|c|c|}
\hline \multirow[b]{2}{*}{ Foods } & \multicolumn{3}{|c|}{ Clusters at 1 year of age $(n 719)$} & \multicolumn{3}{|c|}{ Clusters at 3 years of age $(n 708)$} & \multicolumn{3}{|c|}{ Clusters at 6 years of age $(n 841)$} \\
\hline & Healthy & Traditional & Ready-to-eat baby food & Healthy & Traditional & Fast food, sweets & Healthy, low-fat & Traditional & Fast food, sweets \\
\hline Baby/infant formulas & -0.12 & -0.13 & $0.23^{\star}$ & & & & & & \\
\hline Baby fruit-berry purée & & -0.16 & 0.14 & & 0.11 & -0.11 & & & \\
\hline Baby meat dishes & & $-0.30^{*}$ & $0.34^{*}$ & & & & & & \\
\hline Baby milk porridge & & $-0.23^{*}$ & $0.22^{*}$ & & & & & & \\
\hline Porridge & & $0.21^{*}$ & $-0.21^{*}$ & $0.24^{*}$ & & $-0.23^{\star}$ & & & -0.19 \\
\hline Bakery savoury & & & & -0.10 & & 0.16 & & & $0 \cdot 16$ \\
\hline Bakery sweet & & $0 \cdot 20^{*}$ & -0.18 & & & & & & \\
\hline Bread, white wheat & & 0.16 & -0.16 & -0.19 & & $0.21^{*}$ & -0.14 & & 0.14 \\
\hline Bread, whole cereal & 0.15 & 0.12 & $-0.24^{\star}$ & 0.15 & & & $0.24^{*}$ & & -0.18 \\
\hline Berry dishes & & $0.32^{*}$ & $-0.27^{\star}$ & $0.22^{*}$ & & -0.19 & 0.12 & & -0.14 \\
\hline Fruits & & & -0.16 & & & & $0 \cdot 10$ & & -0.11 \\
\hline Meat dishes and products & & $0.32^{*}$ & $-0.30^{*}$ & & & & & & $-0 \cdot 11$ \\
\hline Meat, poultry dishes & & $0.26^{*}$ & $-0.29^{*}$ & & $0.28^{*}$ & $-0.27^{\star}$ & & -0.18 & 0.12 \\
\hline Sausage dishes, cold cuts & & $0.23^{*}$ & -0.19 & & -0.13 & 0.12 & & & \\
\hline Fish dishes & & & -0.15 & $0.26^{*}$ & -0.17 & & 0.11 & & \\
\hline Milk desserts & 0.12 & & -0.19 & $-0.21^{*}$ & & 0.19 & & & \\
\hline Milks, skimmed, low-fat & $0.36^{*}$ & & $-0.20^{\star}$ & 0.13 & $-0.21^{*}$ & & $0.35^{\star}$ & $-0.37^{\star}$ & \\
\hline Milks, high-fat & -0.17 & $0.25^{\star}$ & & & $0.23^{*}$ & -0.12 & $-0.27^{\star}$ & $0.42^{*}$ & $-0.20^{\star}$ \\
\hline Yoghurt & 0.11 & & -0.18 & & & & & & \\
\hline Cheeses & $0.38^{*}$ & & $-0.24^{\star}$ & & & & & & \\
\hline Potatoes & & $0.38^{*}$ & $-0.36^{\star}$ & & -0.12 & & & 0.15 & -0.17 \\
\hline Potatoes, fried or creamy & & & & -0.15 & & 0.14 & -0.16 & -0.12 & $0.32^{*}$ \\
\hline Sweets, chocolate and sugar & & $0 \cdot 16$ & -0.16 & -0.13 & & $0 \cdot 16$ & & & 0.14 \\
\hline Nuts, dried fruit, chips & & & & 0.23 & & -0.15 & & & $0.22^{\star}$ \\
\hline Sweetened beverages & & & & & -0.12 & 0.17 & $-0.21^{\star}$ & & $0.34^{\star}$ \\
\hline Waters & & & & & & & & -0.12 & 0.17 \\
\hline Dairy spread & & $0 \cdot 10$ & -0.11 & -0.15 & $0.36^{*}$ & $-0 \cdot 16$ & $-0.22^{\star}$ & 0.19 & \\
\hline Fat spread, margarine & & $0.30^{*}$ & $-0.25^{\star}$ & 0.15 & $-0.39^{\star}$ & 0.18 & $0.25^{\star}$ & -0.14 & -0.12 \\
\hline Vegetables, cooked & $0.29^{*}$ & & $-0.28^{\star}$ & $0.22^{*}$ & & $-0.20^{*}$ & 0.16 & -0.12 & \\
\hline Vegetables, fresh & 0.18 & 0.13 & $-0.27^{\star}$ & & & & 0.13 & & \\
\hline
\end{tabular}

${ }^{*}$ Coefficients $\leq-0.20$ or $\geq 0.20$ 


\section{Statistical methods}

\section{Data handling procedures}

Forty-nine and fifty-two selected food groups were used to form the clusters of children and mothers, respectively. Foods that were consumed by less than $10 \%$ of the individuals in each age group were omitted from the analysis. Such variables play little role in the description of typical behaviour, but often have undesirable effects on the group structure in terms of very small clusters of outliers. Items with a very skew distribution were coded as binary $0-1$ variables, indicating whether the item was consumed at all or not. Continuous variables were winsorised at the 95th quantile (to avoid distortion by outliers), and then standardised to zero mean and unit variance before the analysis.

\section{Hierarchical cluster analysis}

After pre-processing of the data, the individuals were grouped by Ward's minimum variance method ${ }^{(36)}$ implemented in SAS/PROC CLUSTER (SAS Institute, Cary, NC, USA). Boys and girls were not separated in the analysis. Different numbers of clusters were considered, and the one with the most realistic grouping was selected for reporting. Spearman's rank correlations between cluster indicator variables and the food items were estimated in order to describe cluster characteristics relative to the other groups. The rank correlation was selected because it measures here the general tendency of values to be greater (or smaller) in one group than in the others, but omits the scale of using only the rankings. Summary statistics ( $n$, mean, interquartile range) were used to quantify absolute differences between the groups of children and mothers.

\section{Analysis of associations}

The associations between the background characteristics, mother's and children's dietary clusters were assessed by frequency tables and by $\chi^{2}$-tests for the null hypothesis of independence of rows (the mother's cluster) and columns (the child's cluster). Statistical significance was taken as less than $5 \%$ (two-sided). The associations between cluster membership and background variables (sex, day care, maternal age, number of siblings, basic and professional education of the mother) were investigated by logistic regression models using one and multiple explanatory variables. Obsolete and overlapping effects and second-order interactions were eliminated from the multiple logistic regression model using model selection procedures. Chosen models were not sensitive to the choice of selection procedure.

\section{Results}

Hierarchical cluster analysis resulted in three main dietary clusters in the age groups of 1,3 or 6 years (Table 1). The 'healthy' or 'healthy, low-fat' dietary cluster was detected for each age group with high correlations in skimmed milk, whole-grain bread and vegetables. The 'traditional' cluster with a relatively high intake of dairy spread and high-fat milk was also determined for all ages. The Spearman correlation coefficients between clusters and food consumption varied, however, by age. The cluster 'fast food, sweet' had the highest positive coefficients with the intakes of sugarsweetened beverages, fried potatoes, chips, nuts and dried fruit in 3- and 6-year-old children. In infants, the cluster 'ready-to-eat, baby foods' had high positive coefficients with intakes of infant formulas and manufactured baby foods and negative coefficient with intakes of potatoes, vegetables, bread and spread.

The differences in food consumption profiles were remarkable for the clusters of 6-year-old children, e.g. consumption of milks, soft drinks, potato or berry dishes, but slightly smaller among younger children (Tables 2-4). Similarly, for some food groups, the consumer proportion was less than $25 \%$ as shown by the lower quartile value of 0 . Even 6-year-old children consumed few food items in $3 \mathrm{~d}$ and the lower quartile

Table 2. Consumption statistics of main food groups ( $\mathrm{g} / \mathrm{d}$ measured by 3-d food records) in the dietary clusters of 1-year-old children (Mean values and interquartile ranges)

\begin{tabular}{|c|c|c|c|c|c|c|}
\hline \multirow[b]{2}{*}{ Food group } & \multicolumn{2}{|c|}{ Healthy ( $n$ 147) } & \multicolumn{2}{|c|}{ Traditional ( $n$ 258) } & \multicolumn{2}{|c|}{$\begin{array}{l}\text { Ready-to-eat baby foods } \\
\qquad(n \text { 314) }\end{array}$} \\
\hline & Mean & Interquartile range & Mean & Interquartile range & Mean & Interquartile range \\
\hline Baby fruit purée & 72 & $33-105$ & 60 & $7-97$ & 84 & $33-125$ \\
\hline Baby meat dishes & 105 & $33-165$ & 78 & $0-133$ & 159 & $72-225$ \\
\hline Baby milk porridge & 96 & $0-189$ & 64 & $0-83$ & 146 & $0-244$ \\
\hline Milk infant formula & 130 & $0-213$ & 149 & $0-274$ & 254 & $0-447$ \\
\hline Porridge & 211 & $74-322$ & 252 & $130-373$ & 174 & $0-277$ \\
\hline Bread, whole cereal & 12 & $2-18$ & 10 & $1-14$ & 7 & $0-7$ \\
\hline Berry dishes & 12 & $0-10$ & 38 & $0-71$ & 6 & $0-1$ \\
\hline Meat dishes & 34 & $0-50$ & 68 & $10-98$ & 30 & $0-34$ \\
\hline Milks, skimmed, low-fat & 159 & $0-300$ & 39 & $0-0$ & 20 & $0-0$ \\
\hline Milks, high-fat & 59 & $0-67$ & 204 & $0-352$ & 115 & $0-147$ \\
\hline Yoghurt & 64 & $10-100$ & 63 & $0-100$ & 44 & $0-67$ \\
\hline Potato & 48 & $0-75$ & 85 & $25-133$ & 26 & $0-42$ \\
\hline Dairy spread & 1 & $0-0$ & 1 & $0-0$ & 0 & $0-0$ \\
\hline Fat spread, margarine & 1 & $0-1$ & 2 & $0-3$ & 1 & $0-0$ \\
\hline Vegetables, cooked & 44 & $0-50$ & 6 & $0-7$ & 2 & $0-0$ \\
\hline Vegetables, fresh & 10 & $0-12$ & 7 & $0-10$ & 3 & $0-2$ \\
\hline
\end{tabular}


Table 3. Consumption statistics of main food groups ( $\mathrm{g} / \mathrm{d}$ measured by 3-d food records) in the dietary clusters of 3-year-old children (Mean values and interquartile ranges)

\begin{tabular}{|c|c|c|c|c|c|c|}
\hline \multirow[b]{2}{*}{ Food group } & \multicolumn{2}{|c|}{ Healthy ( $n$ 182) } & \multicolumn{2}{|c|}{ Traditional ( $n$ 139) } & \multicolumn{2}{|c|}{ Fast food, sweets ( $n$ 387) } \\
\hline & Mean & Interquartile range & Mean & Interquartile range & Mean & Interquartile range \\
\hline Bread, whole cereal & 39 & $22-53$ & 30 & $14-46$ & 31 & $16-43$ \\
\hline Porridge & 161 & $72-229$ & 131 & $25-197$ & 97 & $0-143$ \\
\hline Berries & 7 & $0-0$ & 3 & $0-0$ & 4 & $0-0$ \\
\hline Berry dishes & 71 & $3-125$ & 47 & $0-76$ & 33 & $0-50$ \\
\hline Fruit, fresh & 52 & $8-82$ & 57 & $5-86$ & 48 & $2-70$ \\
\hline Meat dishes & 17 & $0-22$ & 31 & $0-56$ & 9 & $0-13$ \\
\hline Meat, poultry & 102 & $50-143$ & 104 & $50-140$ & 104 & $46-148$ \\
\hline Fish dishes & 36 & $0-67$ & 8 & $0-10$ & 13 & $0-21$ \\
\hline Milks, skimmed, low-fat & 197 & $0-333$ & 61 & $0-75$ & 134 & $0-217$ \\
\hline Milks, high-fat & 198 & $0-347$ & 313 & $150-450$ & 185 & $30-300$ \\
\hline Potato & 58 & $20-80$ & 42 & $0-60$ & 58 & $20-80$ \\
\hline Drinks, berry-based & 103 & $10-160$ & 86 & $0-117$ & 122 & $33-183$ \\
\hline Sweetened beverages & 15 & $0-25$ & 14 & $0-0$ & 36 & $0-50$ \\
\hline Nuts, dried fruit, chips & 6 & $0-10$ & 2 & $0-0$ & 2 & $0-1$ \\
\hline Sweets, sugar & 8 & $2-11$ & 10 & $2-14$ & 14 & $3-20$ \\
\hline Dairy spread & 1 & $0-1$ & 6 & $0-9$ & 2 & $0-2$ \\
\hline Fat spread, margarine & 8 & $3-12$ & 2 & $0-4$ & 8 & $3-12$ \\
\hline Vegetables, cooked & 46 & $0-53$ & 18 & $0-20$ & 13 & $0-13$ \\
\hline Vegetables, fresh & 34 & $5-50$ & 25 & $2-40$ & 29 & $4-43$ \\
\hline
\end{tabular}

was 0 for many food groups (Table 4). The consumption of sweetened beverages was 3-fold for 6-year-old members of the cluster 'fast food, sweets' compared with the members of the cluster 'modern, healthy'. Even the lower quartile consumed sweets daily in all clusters of 3- and 6-year-old children. For 3-year-old children, the mean consumption of potatoes, meat dishes and bread was on the same level by all the clusters but differences existed in the consumption of porridge, cooked vegetables and milk (Table 3).

In the baby cluster 'ready-to-eat baby foods', the consumption of the lower quartile was 0 for most of the food groups except manufactured baby food products (Table 2).
The consumption profile of fruit-based baby foods was as common as in all the three clusters. Instead, manufactured baby foods containing meat or cereals were common for the infants in the cluster 'ready-to-eat baby foods'. Otherwise, skimmed or low-fat milks and cooked vegetables were common in the cluster 'healthy', while high-fat milk, homemade meat dishes and porridge were common in the cluster 'traditional' among the infants.

The hierarchical cluster analysis of all the mothers enrolled in the DIPP Nutrition Study and giving dietary data ( $n$ 4862) resulted in six main clusters (Table 5). Most mothers belonged to the health-oriented clusters: 'fat conscious'; 'modern,

Table 4. Consumption statistics of main food groups ( $\mathrm{g} / \mathrm{d}$ measured by 3-d food records) in the dietary clusters of 6-year-old children

(Mean values and interquartile ranges)

\begin{tabular}{|c|c|c|c|c|c|c|}
\hline \multirow[b]{2}{*}{ Food group } & \multicolumn{2}{|c|}{ Modern, healthy ( $n$ 283) } & \multicolumn{2}{|c|}{ Traditional ( $n$ 360) } & \multicolumn{2}{|c|}{ Fast food, sweets ( $n$ 198) } \\
\hline & Mean & Interquartile range & Mean & Interquartile range & Mean & Interquartile range \\
\hline Bakery savoury & 20 & $0-32$ & 21 & $0-33$ & 36 & $0-56$ \\
\hline Bakery sweet & 24 & $4-36$ & 27 & $8-39$ & 30 & $8-44$ \\
\hline Bread, whole cereal & 59 & $35-77$ & 45 & $25-61$ & 38 & $21-49$ \\
\hline Pizza & 10 & $0-0$ & 11 & $0-0$ & 16 & $0-17$ \\
\hline Porridge & 103 & $36-143$ & 105 & $10-161$ & 65 & $0-107$ \\
\hline Berry dishes & 58 & $3-98$ & 48 & $0-71$ & 37 & $0-50$ \\
\hline Fruit, fresh & 61 & $16-89$ & 51 & $3-81$ & 40 & $0-64$ \\
\hline Meat dishes & 126 & $67-167$ & 137 & $64-190$ & 108 & $50-150$ \\
\hline Fish dishes & 27 & $0-33$ & 21 & $0-27$ & 14 & $0-17$ \\
\hline Milks, skimmed, low-fat & 304 & $67-469$ & 101 & $0-158$ & 197 & $0-333$ \\
\hline Milks, high-fat & 168 & $0-250$ & 362 & $183-517$ & 170 & $0-247$ \\
\hline Potato & 66 & $27-100$ & 75 & $33-107$ & 49 & $18-72$ \\
\hline Potato, fried & 6 & $0-0$ & 8 & $0-0$ & 22 & $0-33$ \\
\hline Drinks, berry-based & 90 & $0-133$ & 154 & $31-233$ & 92 & $11-133$ \\
\hline Sweetened beverages & 31 & $0-50$ & 44 & $0-67$ & 109 & $0-167$ \\
\hline Drinks, water & 107 & $0-167$ & 95 & $0-133$ & 164 & $33-244$ \\
\hline Nuts, dried fruit, chips & 2 & $0-1$ & 2 & $0-1$ & 7 & $0-10$ \\
\hline Sweets, sugar & 18 & $3-25$ & 19 & $5-26$ & 26 & $7-38$ \\
\hline Dairy spread & 2 & $0-1$ & 4 & $0-7$ & 4 & $0-5$ \\
\hline Fat spread, margarine & 12 & $6-16$ & 8 & $2-12$ & 7 & $3-11$ \\
\hline Vegetables, fresh & 40 & $13-60$ & 34 & $7-47$ & 32 & $9-41$ \\
\hline
\end{tabular}


Table 5. Consumption statistics of main food groups ( $g / d$ by a FFQ) by the six clusters in the mothers of the Diabetes Prediction and Prevention Nutrition Study included in hierarchical cluster analysis (Mean values and interquartile ranges)

\begin{tabular}{|c|c|c|c|c|c|c|c|c|c|c|c|c|}
\hline \multirow[b]{2}{*}{ Food group } & \multicolumn{2}{|c|}{$\begin{array}{l}\text { Fat conscious } \\
\quad(n 1144)\end{array}$} & \multicolumn{2}{|c|}{$\begin{array}{l}\text { Modern, healthy } \\
\quad(n \text { 887) }\end{array}$} & \multicolumn{2}{|c|}{$\begin{array}{l}\text { Small amounts } \\
\quad(n 1240)\end{array}$} & \multicolumn{2}{|c|}{$\begin{array}{l}\text { Fast food, plenty } \\
\qquad(n 418)\end{array}$} & \multicolumn{2}{|c|}{$\begin{array}{l}\text { Refined, sugar and but- } \\
\operatorname{ter}(n 607)\end{array}$} & \multicolumn{2}{|c|}{$\begin{array}{l}\text { Fast food, sweets } \\
\qquad(n 566)\end{array}$} \\
\hline & Mean & $\begin{array}{l}\text { Interquartile } \\
\text { range }\end{array}$ & Mean & $\begin{array}{l}\text { Interquartile } \\
\text { range }\end{array}$ & Mean & $\begin{array}{l}\text { Interquartile } \\
\text { range }\end{array}$ & Mean & $\begin{array}{l}\text { Interquartile } \\
\text { range }\end{array}$ & Mean & $\begin{array}{l}\text { Interquartile } \\
\text { range }\end{array}$ & Mean & $\begin{array}{l}\text { Interquartile } \\
\text { range }\end{array}$ \\
\hline Bakery sweet, high-fat & 17 & $7-23$ & 18 & $8-25$ & 18 & $7-23$ & 44 & $18-57$ & 33 & $14-40$ & 29 & $10-39$ \\
\hline Bakery sweet, low-fat & 22 & $7-29$ & 27 & $10-36$ & 27 & $7-36$ & 41 & $14-57$ & 52 & $16-64$ & 25 & $7-32$ \\
\hline Bakery savoury & 16 & $8-21$ & 22 & $10-28$ & 14 & $6-18$ & 32 & $13-38$ & 25 & $12-32$ & 20 & $8-25$ \\
\hline Bread, dark & 88 & $36-140$ & 100 & $54-142$ & 80 & $35-110$ & 81 & $35-110$ & 89 & $37-140$ & 62 & $19-82$ \\
\hline Bread, white & 62 & $21-90$ & 68 & $30-93$ & 70 & $21-94$ & 79 & $34-111$ & 92 & $44-120$ & 72 & $26-120$ \\
\hline Berries & 34 & $10-45$ & 65 & $21-79$ & 31 & $7-41$ & 64 & $19-81$ & 55 & $15-70$ & 26 & $5-33$ \\
\hline Fruit juice & 221 & $66-340$ & 242 & $73-340$ & 237 & $49-340$ & 442 & $181-594$ & 255 & $73-351$ & 294 & $73-400$ \\
\hline Fruits & 261 & $135-343$ & 296 & $162-385$ & 188 & $82-233$ & 380 & $167-470$ & 234 & $115-297$ & 224 & $93-300$ \\
\hline Meat cuts & 20 & $7-30$ & 22 & $7-30$ & 24 & $7-32$ & 40 & $18-51$ & 34 & $12-48$ & 30 & $11-43$ \\
\hline Meat dishes & 98 & $59-129$ & 111 & $59-148$ & 95 & $59-125$ & 170 & $109-211$ & 122 & $72-158$ & 90 & $53-122$ \\
\hline Meat poultry & 46 & $26-53$ & 49 & $26-53$ & 26 & $12-26$ & 51 & $26-79$ & 33 & $12-53$ & 35 & $18-53$ \\
\hline Sausage & 20 & $6-24$ & 19 & $6-24$ & 20 & $11-24$ & 40 & $24-49$ & 30 & $11-49$ & 25 & $11-24$ \\
\hline Fast food & 23 & $11-31$ & 25 & $13-34$ & 21 & $11-27$ & 57 & $30-71$ & 32 & $16-39$ & 37 & $21-46$ \\
\hline Fish & 46 & $23-61$ & 65 & $34-87$ & 31 & $15-44$ & 68 & $34-92$ & 45 & $22-61$ & 33 & $12-46$ \\
\hline Milks, low-fat & 268 & $0-510$ & 268 & $0-510$ & 215 & $0-340$ & 268 & $0-510$ & 257 & $0-510$ & 183 & $0-340$ \\
\hline Milks, high-fat & 51 & $0-17$ & 78 & $0-49$ & 197 & $0-340$ & 159 & $0-170$ & 186 & $0-340$ & 150 & $0-170$ \\
\hline Milks, sour low-fat & 123 & $34-169$ & 108 & $18-133$ & 49 & $0-71$ & 124 & $21-146$ & 73 & $4-102$ & 64 & $0-102$ \\
\hline Cheese, low-fat & 28 & $2-46$ & 26 & $3-34$ & 6 & $0-7$ & 19 & $2-23$ & 10 & $0-8$ & 10 & $0-8$ \\
\hline Cheese, regular & 30 & $4-43$ & 41 & $10-61$ & 49 & $14-64$ & 51 & $16-70$ & 52 & $17-74$ & 44 & $11-61$ \\
\hline Potato & 82 & $56-111$ & 97 & $56-130$ & 97 & $56-130$ & 108 & $56-130$ & 109 & $56-130$ & 71 & $37-93$ \\
\hline Potato, fried & 15 & $5-21$ & 15 & $5-21$ & 14 & $5-21$ & 38 & $21-46$ & 20 & $10-26$ & 22 & $10-26$ \\
\hline Roots & 44 & $13-53$ & 64 & $24-78$ & 25 & $7-32$ & 54 & $21-71$ & 40 & $13-48$ & 24 & $7-30$ \\
\hline Coffee & 169 & $0-240$ & 170 & $0-240$ & 219 & $4-360$ & 221 & $0-360$ & 225 & $4-360$ & 216 & $0-360$ \\
\hline Tea & 130 & $10-150$ & 185 & $25-300$ & 113 & $5-150$ & 157 & $20-300$ & 155 & $10-300$ & 93 & $10-150$ \\
\hline Beer & 6 & $0-0$ & 6 & $0-0$ & 4 & $0-0$ & 13 & $0-0$ & 6 & $0-0$ & 8 & $0-0$ \\
\hline Chips, dried fruit, nuts & 4 & $0-6$ & 4 & $0-5$ & 4 & $0-5$ & 13 & $5-11$ & 6 & $0-7$ & 10 & $2-11$ \\
\hline Beverages, light & 34 & $0-43$ & 43 & $0-33$ & 24 & $0-22$ & 102 & $0-94$ & 36 & $0-33$ & 120 & $0-141$ \\
\hline Beverages, sugared & 38 & $0-47$ & 37 & $0-47$ & 36 & $0-47$ & 140 & $11-189$ & 53 & $0-76$ & 144 & $0-189$ \\
\hline Sugar & 7 & $2-10$ & 12 & $2-15$ & 7 & $2-10$ & 15 & $4-20$ & 16 & $3-20$ & 8 & $2-10$ \\
\hline Sweet & 9 & $3-11$ & 7 & $3-11$ & 8 & $4-11$ & 21 & $7-25$ & 10 & $4-14$ & 15 & $6-21$ \\
\hline Chocolate & 45 & $8-57$ & 43 & $9-55$ & 53 & $13-58$ & 82 & $29-100$ & 73 & $18-79$ & 72 & $21-80$ \\
\hline Dairy spread & 1 & $0-0$ & 3 & $0-1$ & 2 & $0-0$ & 3 & $0-2$ & 15 & $0-24$ & 5 & $0-3$ \\
\hline Fat spread, low-fat & 7 & $0-12$ & 8 & $0-12$ & 6 & $0-6$ & 5 & $0-6$ & 8 & $0-9$ & 6 & $0-9$ \\
\hline Fat spread, high-fat & 5 & $0-7$ & 5 & $0-6$ & 11 & $0-18$ & 11 & $0-18$ & 6 & $0-3$ & 6 & $0-9$ \\
\hline Vegetables & 112 & $57-136$ & 150 & $81-191$ & 75 & $35-105$ & 143 & $76-184$ & 116 & $56-156$ & 88 & $42-115$ \\
\hline Vegetables, leafy & 37 & $14-50$ & 55 & $28-68$ & 19 & $5-29$ & 49 & $21-65$ & 34 & $11-46$ & 22 & $6-34$ \\
\hline
\end{tabular}


healthy'; or 'small amounts'. Unfavourable dietary elements belonged to the clusters 'fast food, plenty', 'refined, sugar and butter' and 'fast food, sweet' of mothers.

Some familial dependence on dietary clusters was observed in mother-child pairs of 6-year-old children $(P=0.035)$ but not in younger children (Table 6). In 6-year-old children, the cluster 'healthy, low-fat' had a high proportion in the clusters 'fat conscious' and 'modern, healthy' of mothers. A higher frequency than expected was observed for children being members of the cluster 'fast food, sweet' when mother belonged to the cluster 'fast food, plenty', 'refined, sugar and butter' or 'sweet, fast food'. Marginal significance of familiality $(P=0.054)$ at the age of 3 years was observed within child-mother dyads. At the age of 1 year, no indication of familiality was observed.

Associations of social background factors with the dietary patterns were studied for the clusters representing convenience foods, i.e. 'ready-to-eat baby-food' and 'fast foods, sweets' in the age groups of children (Table 7). At the age of 1 year, the cluster 'ready-to-eat baby foods' was prominent for boys and children cared at home, but the cluster was not associated with maternal characteristics. Maternal characteristics, young age and low basic or professional education of the mother, were associated with the cluster 'fast food, sweet' of the child at the age of 3 years. None of the background factors was associated with the cluster 'fast food, sweet' at the age of 6 years.

\section{Discussion}

The consistency between the dietary clusters of the children and their mothers was obvious in the age group of 6-year-olds.
Both the clusters 'healthy, low-fat' and the cluster 'fast food, sweet' in children had a higher frequency than expected in the corresponding clusters of mothers. This is consistent with the earlier results. Similarities in the child-mother pairs have been observed for a prudent $\operatorname{diet}^{(7)}$, fruits and vegetables ${ }^{(4,6)}$, regulation of less-healthy foods ${ }^{(1)}$ but also for high-sugar beverages $^{(2,5)}$. However, the maternal background was not associated with the convenient dietary cluster of that age in the present study, which may also imply the increasing independency of the child in food selections.

The young age and low education of the mother was associated with the convenient dietary cluster only in 3-year-olds. The weak association between convenient dietary clusters in pre-school children and maternal background may result from great differences in dietary habits by age during years of transition from breast-feeding to family food. In previous studies ${ }^{(2,4-6,8)}$, some dependence between food consumption of the children and maternal characteristics has been reported. High maternal education associated by earlier studies with healthy food pattern $^{(7,9,24,27,29)}$ and fibre intake $^{(37)}$, and young age with consumption of high-sugar foods and drinks ${ }^{(8)}$.

For infants and small children, mothers might serve meals or special servings, which may better follow dietary guidelines or assumed guidelines ${ }^{(1)}$. In 1-year-old children of the present study, this may be associated with the cluster 'ready-to-eat baby foods'. In a European comparison, parents in many countries preferred home-made food for their infants ${ }^{(7,13,14)}$ but in Finland, the manufactured baby food products (fruit purée, baby meat products and baby porridge) were served to half of the infants according to the present results as well

Table 6. Consistency in dietary clusters of child-mother dyads ( $n$ 2134)

Clusters of mothers

Fat conscious $(n 184)$

Modern, healthy $(n$ 128)

Small amounts ( $n$ 163)

Fast food, plenty ( $n$ 51)

Refined, sugar and butter ( $n$ 67)

Sweet, fast food $(n 86)$

Fat conscious $(n 179)$

Modern, healthy ( $n$ 127)

Small amounts ( $n$ 159)

Fast food, plenty ( $n$ 46)

Refined, sugar and butter ( $n 75)$

Sweet, fast food $(n 69)$

Fat conscious $(n 181)$

Modern, healthy ( $n$ 143)

Small amounts ( $n$ 215)

Fast food, plenty ( $n$ 68)

Sweet, fast food $(n 78)$
Refined, sugar and butter ( $n$ 115)

Healthy $(n 134)$
31
20
20
9
10
10
100

Traditional $(n 247)$
22
21
29
7
9
11
100

Healthy ( $n$ 174)

25
18
$28 \uparrow$
8
12
9
100



$32 \uparrow \dagger$$$
22
$$$$
20 \downarrow
$$$$
7
$$$$
6 \downarrow
$$$$
12
$$$$
100
$$

Healthy, low-fat ( $n$ 270)

$$
\begin{gathered}
26 \uparrow \\
23 \uparrow \\
25 \\
7 \\
10 \downarrow \\
9
\end{gathered}
$$$$
100
$$

20
$14 \downarrow$
$31 \uparrow$
9
16
9
100

Clusters of 1-year-old children $\left(\chi^{2} P=0 \cdot 286\right)^{*}$
Ready-to-eat baby foods $(n$ 298)
30
16
21
7
10
15
100

Clusters of 3-year-old children ( $\left.\chi^{2} P=0.054\right)$

Fast food, sweet ( $n$ 355)

28
19
19
5
$16 \uparrow$
$13 \uparrow$
100

Clusters of 6-year-old children $\left(\chi^{2} P=0.035\right)$

Fast food, sweet ( $n$ 190)

22
18
23
$9 \uparrow$
$17 \uparrow$
11
100

\section{Total percentage}

27

The cell values are proportions (\%) of the children in clusters of their mothers.

* In 1-year-old infants, the differences are not marked.

†Arrows indicate the differences between the observed and expected cell frequencies that contribute a value of $\geq 1$ to the $\chi^{2}$-test statistic. The arrow $\uparrow$ shows a larger observed frequency and $\downarrow$ shows a smaller observed frequency than expected in 3- and 6-year-old children. 
Table 7. Proportions (\%) of the membership in convenient dietary clusters of children by selected background factors descriptive for the mother-child dyads

\begin{tabular}{|c|c|c|c|}
\hline & $\begin{array}{l}\text { Ready-to-eat baby foods cluster } \\
\text { in 1- year-olds ( } n \text { 298) }\end{array}$ & $\begin{array}{l}\text { Fast food, sweets cluster } \\
\text { in 3- year-olds ( } n 355)\end{array}$ & $\begin{array}{l}\text { Fast food, sweets cluster } \\
\text { in 6- year-olds ( } n \text { 190) }\end{array}$ \\
\hline Sex & $P=0.034^{*}$ & $P=0.855$ & $P=0.991$ \\
\hline Boy & 47 & 54 & 24 \\
\hline Girl & 40 & 55 & 24 \\
\hline Day care & $P=0.002^{*}$ & $P=0.098$ & $P=0.074$ \\
\hline No & 46 & 56 & 27 \\
\hline Yes & 24 & 51 & 22 \\
\hline Maternal age (years) & $P=0.186$ & $P=0.040^{*}$ & $P=0.179$ \\
\hline$<27$ & 40 & 62 & 22 \\
\hline $27-31$ & 43 & 50 & 23 \\
\hline$>31$ & 49 & 52 & 27 \\
\hline Maternal basic education & $P=0.430$ & $P=0.002^{*}$ & $P=0.280$ \\
\hline Less than high school & 46 & $62 \%$ & $26 \%$ \\
\hline High school & 43 & $49 \%$ & $23 \%$ \\
\hline Maternal professional education & $P=0.741$ & $P=0.001^{*}$ & $P=0.429$ \\
\hline Secondary or less & 45 & 58 & 24 \\
\hline University studies or degree & 43 & 43 & 23 \\
\hline
\end{tabular}

${ }^{*} P$ values indicate that the variable was significant at the $10 \%$ level in a multiple logistic regression model after the variable selection procedure.

as in previous Finnish studies ${ }^{(10-12)}$. On the contrary, the infant guideline dietary pattern had negative coefficients for manufactured baby food in the $\mathrm{UK}^{(7)}$.

Three dietary clusters were sufficient for the interpretation of the present results among the children studied. The earlier Finnish study, applying the cluster analysis in 7-year-old children $^{(25)}$, identified four clusters 'cereals', 'sugar and sweets', 'bread and skimmed milk' and 'dairy', which corresponded rather well with the present results in 6-year-old children. The health-conscious pattern as well as fast-food or junk-food pattern have been identified in children by the cluster analysis ${ }^{(24,25)}$ and principal component analyses $^{(7,27-29)}$ in other countries. The basic methodology of the cluster analysis is to group individuals, whereas the factor analysis is to group the variables (foods) ${ }^{(38)}$. The cluster analysis was preferred because it may be easier to interpret as each individual belongs to one cluster only and because it is more applicable to the risk analysis later ${ }^{(38)}$. The present results from the hierarchical cluster analysis in the mothers were partly similar to our previous factor analysis findings from a subpopulation of the same mothers ${ }^{(35)}$. At least, the factors 'healthy', 'low-fat foods' and 'fast food' overlapped the clusters of the present study.

The dietary clusters of the children were based on the FR of $3 \mathrm{~d}$ and, obviously, they do not reflect the whole variety or habits of food selection. Weekend days may differ in the children's diet from that of weekdays ${ }^{(21)}$, but this was controlled for in the present study by guiding the diary recording to cover one weekend day and two weekdays. There are limitations in the present study design to define associations in dietary clusters within mother-child dyads. The study protocol did not give the best opportunity to find the association between the diet of 6-year-old children and their mothers. Our sample may be selected towards a more healthy food behaviour and due to drop-outs the selectivity may be the strongest at the age of 6 years. Furthermore, the background and the diet of the mothers were collected at the time of birth which may hinder the association with the diets of 6 -year-olds. The children studied in the present paper are car- rying increased genetic susceptibility for type 1 diabetes but the dietary clusters correspond to the earlier Finnish results ${ }^{(25)}$. The duration of breast-feeding ${ }^{(11)}$ in the DIPP children also corresponded to the general impression ${ }^{(10)}$. We know little about how parents react to information about increased genetic risk, but it has been shown that information caused no differences at anxiety levels in the parents of high-risk infants compared with the parents of low-risk infants ${ }^{(39)}$.

The type of day care, at home or in kindergarten, seemed to influence the food behaviour, since the proportion of subjects in the cluster 'fast food, sweets' was the lowest among children cared in kindergarten. The present results give evidence for a better dietary quality in children cared outside home ${ }^{(19)}$, but the results are not consistent and vary by nutrient ${ }^{(19,21)}$. Day care outside home covers a considerable proportion of daily food consumption but may be more common for older and more educated mothers. Mothers may have difficulties in putting dietary guidelines into practice at home ${ }^{(1,14,18,20)}$. Dietary counselling has been reported more frequently by nurses than by mothers in visits to child health-care clinics ${ }^{(18)}$. It can be speculated that dietary counselling may not face the practical needs of the family or mothers are too stressed or preoccupied to notice all guidelines offered to them.

None of the infant clusters was associated with the dietary clusters of the mother. Neither the 'ready-to-eat baby foods' cluster in 1-year-old children in the present study was associated with maternal characteristics. Thus, the present results do not confirm previous results ${ }^{(7)}$. Complementary feeding of infants has been started too early compared with the guidelines in many countries ${ }^{(12,14)}$. The high frequency and early introduction of baby foods may give a reason for studying the effects of convenient food habits on later food habits in longitudinal studies. The cross-sectional study design of the present study did not allow for studying longitudinal trends in childhood dietary patterns.

As a conclusion, the present results confirm the concern of consumption of fast foods and high-sucrose sweets and bakery in pre-school children ${ }^{(21,23,26)}$, and therefore the parents 
must be aware of the effect of food available at home. Parents should be encouraged to provide their children healthy food and ensure availability of fruits and vegetables in forms that support the increasing self-regulation of the child.

\section{Acknowledgements}

M. L. O., J. N. and S. M. V. planned the present study and M. L. O. was responsible for writing the article; J. N. was responsible for statistical analysis; L. U., J. J. T. and T. A. prepared the data for the analyses; C. K.-K. coordinated the management of nutrition data; M. K. and R. V. are responsible for the clinical study; S. M. V. has planned the nutrition study within the DIPP project and is responsible for the DIPP Nutrition Study. All the authors read the manuscript and contributed to the writing. None of the authors had any conflicts of interest. Financially supported by: the Academy of Finland (grants 63 672, 79 685, 79686, 80 846, 201988 and 210632); the European Foundation for the Study of Diabetes, the Finnish Diabetes Association; the Finnish Diabetes Research Foundation; the Finnish Pediatric Research Foundation; the Häme Foundation of the Finnish Culture Fund; the Juho Vainio Foundation; the Yrjö Jahnsson Foundation; the European Foundation for the Study of Diabetes; Medical Research Funds, Turku, Oulu and Tampere University Hospitals; the Juvenile Diabetes Research Foundation (grants 197032, 4-1998-274, 4-1999-731 and 4-2001-435); Novo Nordisk Foundation; EU Biomed 2 Program (BMH4-CT98-3314).

\section{References}

1. Alderson T \& Ogden J (1999) What do mothers feed their children and why? Health Educ Res 14, 717-727.

2. Hoerr SL, Lee SY, Schiffman RF, et al. (2006) Beverage consumption of mother-toddler dyads in families with limited incomes. J Pediatr Nurs 21, 403-411.

3. Francis LA, Hofer SM \& Birch LL (2001) Predictors of maternal child-feeding style: maternal and child characteristics. Appetite 37, 231-243.

4. Hannon PA, Bowen DJ, Moinpour CM, et al. (2003) Correlations in perceived food use between the family food preparer and their spouses and children. Appetite 40, 77-83.

5. Fisher JO, Mitchell DC, Smiciklas-Wright H, et al. (2001) Maternal milk consumption predicts the tradeoff between milk and soft drinks in young girls' diets. $J$ Nutr 131, 246-250.

6. Talvia S, Räsänen L, Lagström H, et al. (2006) Longitudinal trends in consumption of vegetables and fruit in Finnish children in an atherosclerosis prevention study (STRIP). Eur $J$ Clin Nutr 60, 172-180.

7. Robinson S, Marriott L, Poole J, et al. (2008) Dietary patterns in infancy: the importance of maternal and family influences on feeding practice. Br J Nutr 99, 1029-1037.

8. Brekke HK, van Odijk J \& Ludvigsson J (2007) Predictors and dietary consequences of frequent intake of high-sugar, lownutrient foods in 1-year-old children participating in the ABIS study. Br J Nutr 97, 176-181.

9. Mikkilä V, Räsänen L, Raitakari OT, et al. (2005) Consistent dietary patterns identified from childhood to adulthood: the cardiovascular risk in Young Finns Study. Br J Nutr 93, 923-931.

10. Hasunen K \& Ryynänen S (2006) Imeväisikäisten ruokinta [Infant feeding in Finland] (In Finnish with English Summary).
In Reports of the Ministry of Social Affairs and Health 19/2005, pp. 70 .

11. Erkkola M, Pigg HM, Virta-Autio P, et al. (2005) Infant feeding patterns in the Finnish type I diabetes prediction and prevention nutrition study cohort. Eur J Clin Nutr 59, $107-113$

12. Freeman V, van't Hof M \& Haschke F (2000) Patterns of milk and food intake in infants from birth to age 36 months: the Euro-growth study. J Pediatr Gastroenterol Nutr 31, Suppl. 1, S76-S85.

13. Synnott K, Bogue J, Edwards CA, et al. (2007) Parental perceptions of feeding practices in five European countries: an exploratory study. Eur J Clin Nutr 61, 946-956.

14. Koehler S, Sichert-Hellert W \& Kersting M (2007) Measuring the effects of nutritional counseling on total infant diet in a randomized controlled intervention trial. J Pediatr Gastroenterol Nutr 45, 106-113.

15. Nasirpour A, Scher J \& Desobry S (2006) Baby foods: formulations and interactions (a review). Crit Rev Food Sci Nutr 46, $665-681$.

16. Alexy U, Sichert-Hellert W, Rode T, et al. (2008) Convenience food in the diet of children and adolescents: consumption and composition. Br J Nutr 99, 345-351.

17. Buckley M, Cowan C \& McCarthy M (2007) The convenience food market in Great Britain: convenience food lifestyle (CFL) segments. Appetite 49, 600-617.

18. Huurre A, Laitinen K, Hoppu U, et al. (2006) How practice meets guidelines: evaluation of nutrition counselling in Finnish well-women and well-baby clinics. Acta Paediatr $\mathbf{9 5}$ $1353-1359$.

19. Ziegler P, Hanson C, Ponza M, et al. (2006) Feeding Infants and Toddlers Study: meal and snack intakes of Hispanic and nonHispanic infants and toddlers. $J$ Am Diet Assoc 106, S107-S123.

20. Krebs NF (2007) Food choices to meet nutritional needs of breast-fed infants and toddlers on mixed diets. J Nutr 137, 511S-517S

21. Garemo M, Lenner RA \& Strandvik B (2007) Swedish preschool children eat too much junk food and sucrose. Acta Paediatr 96, 266-272.

22. Maffeis C, Grezzani A, Perrone L, et al. (2008) Could the savory taste of snacks be a further risk factor for overweight in children? $J$ Pediatr Gastroenterol Nutr 46, 429-437.

23. Ludwig DS, Peterson KE \& Gortmaker SL (2001) Relation between consumption of sugar-sweetened drinks and childhood obesity: a prospective, observational analysis. Lancet 357, 505-508.

24. Knol LL, Haughton B \& Fitzhugh EC (2005) Dietary patterns of young, low-income US children. J Am Diet Assoc 105, 1765-1773.

25. Räsänen M, Lehtinen JC, Niinikoski H, et al. (2002) Dietary patterns and nutrient intakes of 7-year-old children taking part in an atherosclerosis prevention project in Finland. $J$ Am Diet Assoc 102, 518-524.

26. LaRowe TL, Moeller SM \& Adams AK (2007) Beverage patterns, diet quality, and body mass index of US preschool and school-aged children. J Am Diet Assoc 107, 1124-1133.

27. Northstone K \& Emmett P (2005) Multivariate analysis of diet in children at four and seven years of age and associations with socio-demographic characteristics. Eur J Clin Nutr 59, $751-760$.

28. Wiles NJ, Northstone K, Emmett P, et al. (2007) 'Junk food' diet and childhood behavioural problems: results from the ALSPAC cohort. Eur J Clin Nutr (epublication ahead of print version 5 December 2007). 
29. North K \& Emmett P (2000) Multivariate analysis of diet among three-year-old children and associations with sociodemographic characteristics. The Avon Longitudinal Study of Pregnancy and Childhood (ALSPAC) Study Team. Eur J Clin Nutr 54, 73-80.

30. Nicklaus S, Boggio V \& Issanchou S (2005) Food choices at lunch during the third year of life: high selection of animal and starchy foods but avoidance of vegetables. Acta Paediatr 94, 943-951.

31. Kupila A, Muona P, Simell T, et al. (2001) Feasibility of genetic and immunological prediction of type I diabetes in a population-based birth cohort. Diabetologia 44, 290-297.

32. Virtanen SM, Kenward MG, Erkkola M, et al. (2006) Age at introduction of new foods and advanced beta cell autoimmunity in young children with HLA-conferred susceptibility to type 1 diabetes. Diabetologia 49 , $1512-1521$

33. KTL NPHI (2008) ${ }^{\circledR}$ Fineli (Food composition database) Latest version available at http://www.fineli.fi
34. Erkkola M, Karppinen M, Javanainen J, et al. (2001) Validity and reproducibility of a food frequency questionnaire for pregnant Finnish women. Am J Epidemiol 154, 466-476.

35. Arkkola T, Uusitalo U, Kronberg-Kippila C, et al. (2008) Seven distinct dietary patterns identified among pregnant Finnish women - associations with nutrient intake and sociodemographic factors. Public Health Nutr 11, 176-182.

36. Ward JHJ (1963) Hierarchical grouping to optimize an objective function. J Am Stat Assoc 58, 236-244.

37. Garemo M, Arvidsson Lenner R, Nilsson EK, et al. (2007) Food choice, socio-economic characteristics and health in 4-year olds in a well-educated urban Swedish community. Clin Nutr 26, $133-140$.

38. Newby PK \& Tucker KL (2004) Empirically derived eating patterns using factor or cluster analysis: a review. Nutr Rev 62, 177-203.

39. Simonen P, Korhonen T, Simell T, et al. (2006) Parental reactions to information about increased genetic risk of type 1 diabetes mellitus in infants. Arch Pediatr Adolesc Med 160, 1131-1136. 